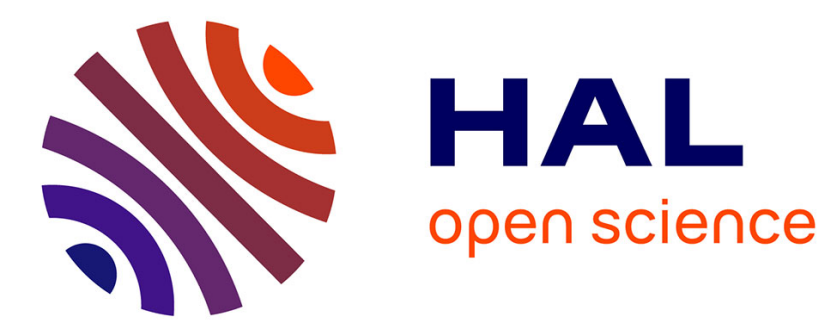

\title{
Convincing consumers to share personal data: double-edged effect of offering money
} Valentine Weydert, Pierre Desmet, Caroline Lancelot Miltgen

\section{To cite this version:}

Valentine Weydert, Pierre Desmet, Caroline Lancelot Miltgen. Convincing consumers to share personal data: double-edged effect of offering money. Journal of Consumer Marketing, 2019, 37 (1), pp.1-9. 10.1108/JCM-06-2018-2724 . hal-02566613

\section{HAL Id: hal-02566613 \\ https://hal.science/hal-02566613}

Submitted on 15 Apr 2021

HAL is a multi-disciplinary open access archive for the deposit and dissemination of scientific research documents, whether they are published or not. The documents may come from teaching and research institutions in France or abroad, or from public or private research centers.
L'archive ouverte pluridisciplinaire HAL, est destinée au dépôt et à la diffusion de documents scientifiques de niveau recherche, publiés ou non, émanant des établissements d'enseignement et de recherche français ou étrangers, des laboratoires publics ou privés. 


\title{
Convincing consumers to share personal data: double-edged effect of offering money
}

\author{
Valentine Weydert \\ University Paris-Dauphine, University PSL, CNRS, DRM, Paris, France \\ Pierre Desmet \\ University Paris-Dauphine, University PSL, CNRS, DRM, Paris, France and ESSEC Business School, \\ Cergy, France \\ Caroline Lancelot-Miltgen \\ Department of Marketing, Audencia Nantes, Nantes, France
}

\section{Abstract}

The purpose of this paper is to demonstrate how offering control on data usage and offering money can increase willingness to share private information with a data broker.

\section{Design/methodology/approach}

Personal data are collected for internet users with a Web questionnaire. In an experimental framework, compensations control money are manipulated and consumers' data sharing is explained by sensitivity and regulatory focus.

\section{Findings}

Offering control increases willingness to disclose personal data, even sensitive one, but the effect is not moderated by regulatory focus.

Offering monetary compensation has a negative, but small, effect on willingness to share personal data, and the effect is moderated by regulatory focus.

\section{$\underline{\text { Keywords }}$}

Control, Privacy, Regulatory focus, Data sharing, Monetary compensation

\section{Published in the}

Journal of Consumer Marketing, Vol. 37 No. 1, pp. 1-9.

DOI 10.1108/JCM-06-2018-2724 
Modern firms must leverage unbiased customer information to implement successful interactive marketing strategies and increase their marketing efficiency by offering more targeted and personalized offers (Hofacker, Malthouse and Sultan, 2015).

Firms can build their own database using transactional data they gather from marketplaces as well as behavioral data from their own website. This data helps companies to better understand the customers already involved with their brands. Increasingly, to achieve this and appeal to prospective customers, they rely on data brokers' datasets. Third party data providers aggregate transactional and behavioral data from a network of retailers' and publishers' websites. They build strategic marketable audiences and then sell them on the digital and advertising markets.

Although a typical data broker business model is based on Business-to-Business relationships with online entities, more and more restrictive data protection legislation (such as the EU General Data Protection Regulation) requires active consent from consumers and calls on data brokers to display the name of their business partners before they can collect data. This regulation has already had an adverse effect on the volume of data collected and on its use. An alternative business model is used by some third party data providers such as Datacoup and Wibson, based on a direct relationship with internet users, i.e. a Business-toConsumer model. To motivate internet users to share their personal information, these companies use compensation incentives such as control over data usage or money.

Offering control over data collection and usage should indeed alleviate privacy concerns (Phelps et al., 2000) as control is increasingly perceived as a right (Novak and Phelps, 1995). Offering money is also a good way to increase data disclosure (Gabisch and Milne, 2014). 
However, this technique may also be considered as an indicator of the profit that can be extracted from the data, thus possibly exacerbating privacy concerns (Andrade et al., 2002; Carrascal et al., 2013) and reducing consumers' motivation to disclose their data.

As data brokers have already experienced issues with privacy (Otto et al., 2006) and data collection practices have only increased consumers' privacy concerns in recent years (Baruh et al., 2017), identifying specific factors that could maximize consumers' willingness to share their personal data with data brokers is crucial, especially as research in this area is still sparse (e.g. Jai and King, 2016). This paper addresses this research question: for data brokers, under which conditions could offering some form of compensation (specifically, control and money) be beneficial or, on the contrary, counterproductive for data sharing?

Understanding the boundary conditions under which compensation strategies (through control or money) may work is crucial, especially as data brokers are mostly unknown to consumers. As trust cannot play a strong role here, consumers assess the situation and decide whether (or not) to share data based on other contextual or individual characteristics. This research focuses on two such variables (i.e. the level of sensitivity of the data collected and the level of regulatory focus) through the lens of regulatory focus theory. This theory serves to highlight the kind of focus (prevention- or promotion-based) individuals adopt when weighing the perceived sensitivity of the requested data against the perceived value of the bargaining offer. More specifically, this theory argues that individuals have a propensity to value concern, as a proxy of control, over personal gain, epitomized in this study by monetary compensation. 
This research makes three main contributions. First, it addresses consumers' willingness to share data with firms that have not been studied previously, namely, data brokers. While the previous literature mostly focuses on known first parties, we study decision-making related to data sharing in the context of unknown third parties. Second, we study the conditions under which the positive effect of monetary compensation could be reversed, for example with money becoming an indicator of the value of the information collected. Third, this research also answers the call for the re-contextualization of privacy research (Lowry, Willison and Dinev, 2017) and the diversification of cultural contexts (Bélanger and Crossler, 2011). Indeed, both culture (e.g. Miltgen and Peyrat Guillard 2014) and regulation (e.g., Markos et al., 2017) are strong determinants of privacy concerns and data sharing. Up to now, privacy research has been heavily reliant on student-based and USA-centric samples. This research offers the opportunity to study privacy using non-US consumers.

The following section contains the theoretical framework, featuring several enablers and moderators of data sharing. After detailing the methodology used to collect the data, the key results are presented. The article concludes with some theoretical and managerial implications and suggestions for further research.

\section{Theoretical framework and hypotheses}

The key drivers of monetary compensation and control function as motivational tools to influence data sharing. Both perceived data sensitivity and individual regulatory focus should in turn moderate this process. In particular, Regulatory Focus theory considers a contextual evaluation of losses and gains (Martin and Murphy, 2017). 
Prior research emphasizes the potential efficiency of providing control over data sharing (e.g. Taylor et al, 2009). Increased data transparency is appealing (Dommeyer and Gross, 2003), and offering active control over the collection and use of data is a key motivation that prompts consumers to disclose private data (Gabisch and Milne, 2014). Such control should decrease privacy concerns (Phelps et al., 2000) and increase people's willingness to share personal information (Phelps et al., 2000), even sensitive information (Prince, 2018). However, the reassuring effect of control may depend on the kind of control offered. Some studies found no effect of control on either privacy concerns or disclosure (Ward et al., 2005), specifically when passive control is offered such as through the display of privacy policy or seals on websites (Milne and Culnan, 2004). In our study, we use a scenario that gives respondents active control over the collection of their data, i.e. they know exactly which data is being collected and the purpose of its usage. We thus assume this active control will positively influence respondents' decision to share their data with the data broker. Therefore:

Hla: Offering active control increases willingness to share personal data.

While monetary compensation could be considered as an indicator of the profit companies can extract from consumers' data, thus reducing their intention to disclose data (GomezBarroso, 2018; Marreiros et al., 2017), it may also be perceived more positively. In particular, based on the privacy calculus, consumers should agree to share personal data in exchange for some monetary compensation (Phelps et al., 2000; Li et al., 2010). Some studies have indeed concluded that offering a monetary reward could increase personal information disclosure (Acquisti, 2004; Hann and Lee, 2007; Mukherjee et al., 2013). Consumers also seem to appreciate companies offering money in exchange for their personal data (Gabisch and Milne, 2014). Therefore, following mainstream economic research in this area, we propose: 
H1b: Offering monetary compensation increases willingness to share personal data.

The sensitivity of the data collected is a widely studied situational factor that influences data sharing (Malhotra et al., 2004). Perceived data sensitivity is situational and varies with the context, the nature of the data collected (Li et al., 2010), and the individual sensitivities to personal data exploitation (Acquisti and Grossklags, 2005). For example, demographic and lifestyle data tend to be seen as less sensitive than financial or health-related information (Phelps et al., 2000). According to Mosteller and Poddar (2017), data sensitivity stimulates people to think about preventing privacy invasions and thus reduces intentions to share personal data (Acquisti, 2004; Lwin et al., 2007). Therefore:

H2: Willingness to share personal data decreases with perceived sensitivity of the data.

The perceived value provided by offering control is related to data sensitivity. For low sensitive data, the perceived potential loss on privacy rights is low, the opposite being true for highly sensitive data. Therefore:

H3: The higher data sensitivity, the lower the effect of offering control on willingness to share personal data

Regulatory focus could directly influence willingness to disclose personal data and also moderate the effects of both forms of compensation. Regulatory Focus Theory informs investigations of consumer behavior and decision-making in various contexts, including information searches and preference construction (Wang and Lee, 2006) as well as willingness to share personal data (Mosteller and Poddar, 2017). Self-regulation theory stems from social science and psychology research (Higgins, 2002), citing people's motivation and ability to direct their behavior and control their impulses to meet certain standards, achieve 
certain goals, or reach certain ideals. It examines the relationship between people's motivation and the path they choose to achieve a goal, in a way that maintains their own personal values and beliefs known as regulatory orientation. In the regulatory focus framework (Higgins, 2002), individual decision-making is guided by motivational systems, or regulatory focus, which reflects desires either to approach (promotion) or avoid (prevention) a particular end state. With a promotion focus, people worry about advancement, growth and accomplishment; they need nurturing and their actions are motivated by hope and aspiration for reaching some achievement or ideal. Conversely, with a prevention focus, people are concerned with safety, protection and responsibility, so their actions are motivated by a sense of duty and necessity, enabling them to reach avoidance and "ought goals". Prevention-focused people exhibit more vigilance in their actions in order to reach avoidance goals (Poels and Dewitte, 2008) and should be less willing to share their data than those oriented toward promotion. They are more concerned about privacy (Mosteller and Poddar, 2017), assign more importance to privacy rights and consider that their personal data is an asset to protect and not a mean for specific goal achievement (e.g., personalized offer). Therefore:

H4: For promotion-focused (prevention-focused) consumers, willingness to share personal data is higher (lower)

Regulatory focus could moderate the effect of data sensitivity on willingness to share data. Regulatory Focus theory suggests that consumers who seek to avoid loss and ensure the absence of negative outcomes (i.e. prevention-focused) adopt preventative behavior to protect their privacy and reduce the threat of unauthorized data access or usage, such that they should be less willing to share data, whatever the level of data sensitivity. On the contrary, consumers who pursue gains and favor the presence of positive outcomes (promotion- 
focused) prefer immediate monetary rewards (vs. control) and attach less value to privacy rights. Offering compensation will have a stronger effect on their decision. Nevertheless, this does not mean they are not concerned about privacy.

H5a: For promotion-focused (prevention-focused) consumers, the effect of data sensitivity on willingness to share personal data is larger (smaller).

Regulatory focus could moderate the moderating effect of data sensitivity on the effects of compensation strategies on willingness to share data. For prevention-focused consumers, control is mandatory and the moderating effect of data sensitivity on offering control should be low (i.e. small differences between high and low data sensitivity), unlike promotionfocused consumers, who value control only when highly sensitive data is at stake (i.e. high value placed on control only for highly sensitive data). The effect of monetary compensation also depend on an interaction between sensitivity of the information requested (Xu et al., 2009) and regulatory focus. As promotion-focused people are more willing to give access to their personal data for monetary compensation (Mosteller and Poddar, 2017), it is expected that the effect of offering money will be larger for low sensitivity data. Therefore:

H5b: For promotion-focused (prevention-focused) consumers, the moderating effect of data sensitivity on the effect of offering control on willingness to share personal data is larger (smaller).

H5c: For promotion-focused (prevention-focused) consumers, the moderating effect of data sensitivity on the effect of offering monetary compensation on willingness to share personal data is larger (smaller). 
The conceptual model (see Figure 1) describes the direct effect of the compensations offered by data brokers (control and monetary) on consumers' willingness to share personal data and the moderating effect of perceived data sensitivity. We also hypothesize that regulatory focus will moderate the effects of data sensitivity on the compensation effects.

< Insert Figure 1 about here >

\section{Methodology}

Sample

An online questionnaire (using Qualtrics) was administered to a sample of French consumers recruited on social media (Facebook and LinkedIn public groups) $(n=201)$. The sample characteristics are very similar to those of the French population in terms of gender split (49\% of women), age (mean $=40)$, professional activity (17\% students), use of browsers (Google Chrome and Firefox 71\% versus 74\%, ZDNet, 2016) and number of annual online purchases (21 in the sample versus 23 in the population, Fevad, 2016).

\section{Experiment design}

Participants read a scenario that describes the offer of a data broker that wants to access their browsing data (e.g., Google searches, videos viewed), using a cookie that would be placed on their computer. The data broker is presented as an unknown third party, to avoid any potential bias effect of the broker's image on trust (Hann et al., 2007). The scenario explains that the broker will make the data anonymous, aggregate it with thousands of other users' data to obtain general trends that will be sold to marketers. 
Compensations are manipulated in a 2 (monetary compensation yes/no) $\times 2$ (control over data yes/no) between-subjects factorial design with random allocation. Previous research has often proposed a small amount of money to obtain disclosure. For example, Premazzi et al. (2010) offer a \$20 US coupon for personal identification and financial data. We retain a value of $€ 60$ (\$67 US) per year as monetary compensation. This amount reflects the average amount offered by real-world data brokers for full access to Internet users' social media and purchasing behavior and is thus correlated with the real value of this data. For control over data usage, the scenario promises active transparency, "the ability to control to whom the data broker sells the data and what will be done with it" (presence case). In the absence of any compensation (money or control), respondents read a description of the intrinsic benefits of online data sharing, including the "benefit from personalized commercial offering, targeted advertising related to your browsing preferences."

A validation check with a national panel (Toluna) confirms the manipulation is effective for money $(\mathrm{n}=98 ; \mathrm{t}=-8.49, \mathrm{p}<.01)$ and control $(\mathrm{n}=99 ; \mathrm{t}=-12.59, \mathrm{p}<.01)$.

\section{Measures}

Measures, descriptive statistics and correlations are presented in Table 1. Willingness to share personal data (Phelps et al., 2000) and perceived data sensitivity (Lancelot-Miltgen, 2009) are measured on a 7-point scales. Situational regulatory focus scale combines both emotional appraisal and outcome values, two different but correlated dimensions (Higgins, 2002) and is the difference between promotion and prevention scores, themselves computed as combinations of two emotional appraisals and two perceived outcome value, such that a higher score implies a stronger focus on promotion. 
< Insert Table 1 about here >

\section{Control variables}

Demographics (age and gender) are selected as control variables as they play an important role in privacy-related research and their role has been specifically identified in the case of data sharing with third-party firms (Jai and King, 2016). Privacy concerns seem to be greater amongst older consumers and women (Cho and Hung, 2011).

\section{Statistical analysis and results}

Although data were collected in one survey, common method bias assessed by Harman's single-factor test is not critical. Measured variables are mean-centered and statistical effects are estimated using a hierarchical regression. The assumption of homogeneity of variances for data sharing across the experimental cells is supported (Levene test $(3,197)=2.08, \mathrm{p}=.104)$.

Estimated coefficients for covariates (gender, age) are not significant. If gender has no significant effect, the effect of age on willingness to disclose is indeed supported but fully mediated by data sensitivity. Age does indeed decrease intention to share personal data when regulatory focus and data sensitivity are absent $(\mathrm{t}=-2.91, \mathrm{p}<.01)$, but this effect vanishes when these variables are introduced as age is positively related to perceived data sensitivity ( $t$ $=3.91, \mathrm{p}<.01)$ and negatively to promotion-oriented regulatory focus $(\mathrm{t}=-2.94, \mathrm{p}<.01)$. Results are presented in Table 2.

< Insert Table 2 about here >

The model is statistically significant $\left(\mathrm{F}(13,187)=9.13, \mathrm{p}<.01 ; \mathrm{R}^{2}=39.7 \%\right)$. Offering control over data usage has a positive effect on data sharing $(\mathrm{F}(1,187)=12.00 ; \mathrm{p}<.01)(\mathrm{H} 1 \mathrm{a}$ 
supported) while the effect size is small $\left(\mathrm{SP} \mathrm{Eta}^{2}=.039\right)$. The estimated coefficient for monetary compensation is statistically significant but in the opposite direction of what was expected (H1b reversed): offering a high amount of money decreases willingness to share data.

As expected, data sensitivity has the strongest effect $\left(\mathrm{SP} \mathrm{Eta}^{2}=.237\right)$ on willingness to share personal data and reduces it (H2 supported). Data sensitivity moderates the effect of control $(\mathrm{F}(1,187)=10.20 ; \mathrm{p}<.01)(\mathrm{H} 3$ supported $)$ although the effect size is small $\left(\right.$ SP Eta ${ }^{2}=$ .033). The higher data sensitivity, the lower the effect of offering control on willingness to share personal data.

Regulatory focus has no direct effect on willingness to share data (H4 not supported) and does not moderate the moderating effect of data sensitivity on the effect of control (H5a not supported). However, the moderated moderation of data sensitivity by regulatory focus is statistically significant for monetary compensation $(\mathrm{F}(1,187)=4.07, \mathrm{p}=.045)$. For prevention-focused consumers offering monetary compensation has no significant effect on willingness to share data; for promotion-focused consumers, offering a large amount of money as compensation significantly decreases willingness to share when collected data is of low sensitivity but has no effect for highly sensitive data (H5b supported).

The panel in Figure 2 presents interaction graphs. In a "pick-a-point" approach, three points are selected (mean-SD, mean, mean $+\mathrm{SD}$ ) for both data sensitivity and regulatory focus. Panel (2.a) presents willingness to share (Y) by data sensitivity (X) for three levels of regulatory focus (prevention, neutral, promotion); Panels (2.b and 2.c) present willingness to 
share (Y) by data sensitivity (X) depending on the compensation (control, money), for the same three levels of regulatory focus (prevention, neutral, promotion).

\section{$<$ Insert Figure 2a, 2b and 2c about here>}

Several conclusions can be drawn. First, willingness to share data with a data broker is low and strongly decreases with data sensitivity. Second, the effect of perceived data sensitivity is moderated by regulatory focus: willingness to share is less influenced by data sensitivity for prevention-oriented people than for promotion-oriented people, who are less reluctant to share data they perceive as less sensitive. However, when the data is perceived as highly sensitive, willingness to share is the same, whatever the level of regulatory focus. Third, offering control is an effective way to increase data sharing but the size of the effect decreases as perceptions of data sensitivity increase. Both promotion- and prevention-oriented consumers value control. Fourth, although prevention-oriented consumers do not want to trade their privacy for money, it appears that offering money has an adverse effect on data sharing: a high amount of money decreases willingness to share data for promotion-oriented people when the sensitivity of the data is perceived as low.

\section{Discussion and conclusion}

For marketers, collecting data through data brokers is appealing as these third parties can simultaneously protect consumers' interests and privacy while still granting marketers access to personal data. Data brokers are currently extending their business model from B2B to B2C by collecting data directly from consumers. To stimulate data sharing, they offer compensation to consumers in the form of either monetary rewards or more control over data transmission and usage. For example, a consumer can decide to disclose anonymous 
information to Wibson about location and individual information about social media and Google accounts for $\$ 10$ a month. In testing the effects of both forms of compensation on data sharing while taking into account the perceived sensitivity of the data, this study assesses the moderating effects of individual approaches (though their regulatory focus) to a situation.

The support for the main hypotheses regarding control and the notable results on monetary compensation in turn provide several pertinent insights for both researchers and marketers.

First, consumers exhibit low willingness to share personal data with a data broker, probably because the level of trust in the unknown data broker is low (Premazzi et al., 2010). Furthermore, the greater the perceived data sensitivity, the lower people's intentions to share. However, in line with Benndorf and Normann (2014), consumers do not just completely reject data usage by marketers.

Second, in line with previous research (e.g. Malhotra et al. 2004), this study confirms that the best way to increase data sharing is to reduce the risk associated with the use of personal data. Offering more control, by enhancing awareness about data collection, aggregation and usage, may be an effective strategy for reducing perception of risks, ensuring security and making people more comfortable with personal data sharing (see also Wu et al., 2012). Globally, these results enrich previous findings by showing that a key challenge for ecommerce is to find ways to highlight the benefits of data collection and usage while providing assurances for minimal risk, to prompt individual data sharing. The current results bring control and transparency to light as tools that businesses can use to make consumers more comfortable with data sharing and ensure the success of their marketing relationship (Culnan and Milberg, 1999). 
Third, the conclusions regarding the effectiveness of monetary-based compensation are stimulating. Experimental studies have indicated that monetary rewards could increase intentions to disclose (Hann and Lee, 2007). However, contextual information is important and the study demonstrates that, for an unknown third party, offering generous monetary compensation has no effect for prevention-oriented consumers and even a negative effect for promotion-focused consumers. As individuals do not seem to be fully aware of the monetary value of their personal data (Malgieri and Custers, 2018), amount of money offered is an indicator of the potential value of the data for the data broker and of the potential privacy protection loss for the consumer (Gabish and Milne, 2014). This conclusion supports another research stream that posits that monetary rewards reduce willingness to share personal data because they increase salience of privacy concerns (Andrade et al., 2002; Marreiros et al., 2017) and consequently of trust (Taylor, Davis and Jillapalli, 2009) through a signaling effect (Boulding and Kirmani, 1993). Alternatively, these results might arise because the data broker represents an unknown entity, unable to reach a minimum acceptable level of trust (Olivero and Lunt, 2004).

\section{Theoretical contributions}

For research in this field, this article offers three main theoretical contributions. First, to the best of our knowledge, it is the only study that simultaneously considers control and monetary compensations. The comparison of these two forms of compensation reveals some important insights, such as that control has a strong, positive influence on data sharing while monetary rewards have a smaller, potentially negative influence. 
Second, this research identifies some boundary conditions of monetary compensation which has a curvilinear effect: initially positive (e.g. Li et al., 2010), an increase of the amount has no effect (Krafft et al., 2017) and could even, as demonstrated in this research, reduce willingness to share data with unknown third parties.

Third, this study confirms that regulatory focus theory offers a relevant framework for analyzing people's attitudes and behavior with regard to personal data disclosure. Wirtz and Lwin (2009) show, in a personal data solicitation context, that trust predicts promotion- (but not prevention-) focused behavior, whereas privacy concerns predict prevention- (but not promotion-) focused behavior. Although previous findings using regulatory focus theory in the context of data privacy acknowledge what Higgins (2003) calls 'the perceived outcome value' (i.e. the perceived value of the final object of the decision), the current findings also enrich the overall regulatory focus theory, especially the theory of transfer value from regulatory fit. Regulatory fit is experienced when people pursue a goal with a specific mindset (e.g. eagerness for a promotion focus and vigilance for a prevention focus) that sustains their regulatory orientation. This regulatory fit has been proven to increase people's perception that a decision they made was "right" which in turn transfers value to the decision outcome, including their willingness to pay more for a product than the people who chose the same product without regulatory fit. In that sense, this research highlights the importance of this mindset (also called value from proper mean (Higgins, 2003)) and challenges the way regulatory focus has been computed in the past. Higgins (2003) proved that when the value from proper mean calls upon the individual's correct regulatory orientation, that individual assigns greater monetary value to the outcome, i.e. the object of the decision (data sharing in this case). 
This study goes further and shows that promotion-focused individuals assign greater monetary value to their data whatever the means used to motivate them as long as the data is not perceived as too sensitive. This result suggests that intangible characteristics of regulatory focus triggered by the overall situational context (i.e. needs, feelings and emotions) might be just as important as tangible characteristics materialized within usual scenarios (i.e. strategic mean, outcome value) in people's decision-making process. The current findings also demonstrate its moderating effect in combination with perceived data sensitivity and monetary compensation: offering monetary compensation has an effect only on promotionoriented consumers and for data of low sensitivity. No matter the regulatory focus, when highly sensitive data is at stake, no incentive can truly motivate individuals to share it. This research proves that even individuals looking for gains remain skeptical when they are offered money in exchange for their information. It appears that regulatory focus theory might help to understand the underlying characteristics of individuals that would explain how they assess data sensitivity.

Consumers looking for gains are more likely to consider the nature of the compensation being offered as a determining element of the decision reached (i.e. data sharing) and have greater potential to consider the monetary value of their data. As the amount proposed for data is a signal of the data value, the amount should stay low for data of low sensitivity.

\section{Empirical and managerial contributions}

This research emphasizes the influence of culture in privacy-related matters as our challenging findings might be the result of cultural differences. It would not be surprising to find different results using a sample of American or Indian respondents as cultural context has 
already been proved to have a strong influence in privacy-related studies (e.g. Lancelot Miltgen and Peyrat-Guillard 2014).

Furthermore, this research offers useful and actionable managerial guidance for marketers in charge of e-commerce and digital and interactive marketing strategies, who need to stimulate consumers' data disclosure, as well as for data brokers seeking appropriate targets who might be interested in their specific services.

First, people's willingness to share personal data with data brokers is low, but it can be increased by granting them with more control. The first step is to reduce risk perceptions by increasing awareness and trust (Marreiros et al., 2017). When their practices and offers will be more widely reported across media and online communities, data brokers may be more likely to attract Internet users' interest and encourage them to make use of the brokerage services.

Second, offering money, at least using the amounts currently proposed by data brokers, can have adverse effects. Firms may thus need to provide non monetary additional value to consumers, such as customized benefits (e.g., premium access to services), to get their data.

Third, the moderating effects of variables such as the regulatory focus emphasizes the need for marketers to adapt their offers to match the identified needs and desires of their targets. Specifically, they should adjust the level of transparency regarding who collects the data and how it will be used (if customers exhibit a prevention focus), or alter the monetary and premium rewards they offer in exchange (if customers have a promotion focus).

\section{Limitations and further research}


The limitations of this study suggest avenues for further research. The sample is from Europe (specifically, France), which has very strict data protection regulations. Noting the vast differences across countries when it comes to regulations (e.g., Gupta et al., 2010) or cultural sensitivity to privacy (e.g. Miltgen and Peyrat Guillard, 2014), the study should be replicated in different countries to determine which boundaries need to be taken into account. Other extensions might investigate a replicable measure for regulatory focus, other variables such as privacy concerns, other measures such as behavioral measures or other methodologies such as experimental tests of data broker recruitment offers. Finally, the results could be extended to other contexts and types of data, beyond an e-commerce context in which the value of the information collected is inherently linked to personalized offers for consumers. In an e-commerce context, the perceived value for the consumer is low, especially compared with the value created in other domains such as health.

\section{References}

Acquisti, A. (2004). Privacy in electronic commerce and the economics of immediate gratification. In Proceedings of the ACM Conference on $5^{\text {th }}$ Electronic Commerce (EC’04), pp. 21-29.

Acquisti, A. and Grossklags, J. (2005). Privacy and rationality in individual decision making. IEEE Security and Privacy, Vol. $3 \mathrm{~N}^{\circ}$ 1, pp. 24-30.Andrade, E.B., Kaltcheva, V. and Weitz, B. (2002). Self- disclosure on the web: the impact of privacy policy, reward and company reputation. Advances in Consumer Research, Vol. 29, pp. 350-353, http://acrwebsite.org/volumes/8674/volumes/v29/NA-29.

Baruh, L., Secinti, E. and Cemalcilar, Z. (2017). Online privacy concerns and privacy management: A meta-analytical review, Journal of Communication, Vol. 67, pp. 2653.

Bélanger, F. and Crossler, R. (2011). Privacy in the digital age: A review of information privacy research in information systems, MIS Quarterly, Vol.35, N4, pp.1017-1041.

Benndorf, V. and Normann, H.-T. (2014). The willingness to sell personal data, DICE Discussion Paper, Düsseldorf Institute for Competition Economics, Paper 143, http://hdl.handle.net/10419/100663. 
Boulding, W. and Kirmani, A. (1993). A consumer-side experimental examination of signalling theory: do consumers perceive warranties as signals of quality? Journal of Consumer Research, Vol. $20 \mathrm{~N}^{\circ}$ 1, pp. 111-123.

Carrascal, J-P., Riederer, C., Erramilli, V., Cherubini, M. and Oliveira, R., (2013). Your browsing behavior for a big mac: economics of personal information online. Proceeding $W W W^{\prime} 13$ Proceedings of the 22nd international conference on World Wide Web, pp. 189-200.

Cho, V., and Hung, H. (2011). The effectiveness of short message service for communication with concerns of privacy protection and conflict avoidance. Journal of ComputerMediated Communication, Vol.16 º2, pp. 250-270.

Culnan, M J. and Milberg, S. (1999). Consumer privacy. In Information Privacy: Looking Forward, Looking Back, Culnan M., Bies R. and Levy M., eds. Georgetown University Press.

Dommeyer, C.J. and Gross, B.L. (2003). What consumers know and what they do: An investigation of consumer knowledge, awareness and use of privacy protection. Journal of Interactive Marketing, Vol. $17 \mathrm{~N}^{\circ}$ 2, pp. 34-51.

Fevad (2016). State of play for French E-Commerce (in French), http://www.fevad.com/2016review-of-e-commerce-in-france-the-70-billion-mark-has-been-reached/

Gabisch, J.A. and Milne, G.R. (2014). The impact of compensation on information ownership and privacy control. Journal of Consumer Marketing, Vol. $31 \mathrm{~N}^{\circ}$ 1, pp.13-26.

Gupta, B., Iyer, L.S. and Weisskirch, R.S. (2010). Facilitation global e-commerce: A comparison of consumers' willingness to disclose personal information online in the USA and in India. Journal of Electronic Commerce Research, Vol. $11 \mathrm{~N}^{\circ}$ 1, pp. 4152.

Hann, I. and Lee, T. (2007). Analyzing online information privacy concerns: An information processing theory approach. In IEEE (Ed.), Hawaii International Conference on System Sciences, Vol. 40, pp.1-10. Hawaii: Computer Society.

Higgins, E.-T. (2002). How self-regulation creates distinct values: The case of promotion and prevention decision making. Journal of Consumer Psychology, Vol. $12 \mathrm{~N}^{\circ}$ 3, pp. 177-191.

Higgins, E-T., Idson L-C., Freitas, A-L., Spiegel, S. and Molden, D-C. (2003). Tranfer of value from fit. Journal of Journal of Personality and Social Psychology, Vol. 84, No. $6,1140-1153$

Hofacker, C. Malthouse, E. and Sultan, F. (2015). Big data and consumer behavior: Imminent opportunities, Journal of Consumer Marketing, Vol. 33 N², pp. 89-97

Jai, T.-M. and King, N. (2016). Privacy versus reward: Do loyalty programs increase consumers' willingness to share personal information with third-party advertisers and data brokers? Journal of Retailing and Consumer Services, Vol. 28, pp. 296-303.

Krafft, M., Arden, C. and Verhoef, P. (2017). Permission marketing and privacy concernsWhy do customers (not) grant permissions? Journal of Interactive Marketing, Vol. 39, pp.39-54. 
Lancelot Miltgen, C. (2009). On-line consumer privacy concern and intention to provide personal data on the Internet. International Journal of Networking and Virtual Organizations, Vol. $6 \mathrm{~N}^{\circ}$ 6, pp. 574-603.

Li, H., Sarathy, R. and Xu, H. (2010). Understanding situational online information disclosure as a privacy calculus. Journal of Computer Information Systems, Vol. $51 \mathrm{~N}^{\circ} 1$, pp. 6271.

Lowry, P., Willison, R. and Dinev, T. (2017). Why security and privacy research lies at the centre of the information system (IS) artefact: Proposing a bold research agenda, European Journal of Information Systems, Vol. 26 №6, pp 546-563

Lwin, M., Wirtz, J. and Williams, J.-D. (2007). Consumer online privacy concerns and responses: a power-responsibility equilibrium perspective. Journal of the Academy of Marketing Science, Vol. $35 \mathrm{~N}^{\circ}$ 4, pp. 572-585.

Malgieri, G. and Custers, B. (2018). Pricing privacy - the right to know the value of your personal data, Computer Law \& Security Review, Vol. 34, 289-303.

Malhotra, N. K., Kim, S. S. and Agarwal, J. (2004). Internet users' information privacy concerns (IUIPC): The construct, the scale and a causal model. Information Systems Research, Vol. $15 \mathrm{~N}^{\circ}$ 4, pp. 336-355.

Martin, K. and Murphy, P. (2017). The role of data privacy in marketing, Journal of the Academy of Marketing Science, Vol.45 N², pp.135-155.

Markos, E., Milne, G. and Peltier, J. (2017). Information sensitivity and willingness to provide continua: A comparative privacy study of the United States and Brazil, Journal of Public Policy \& Marketing, Vol.36 N¹, pp.79-96.

Marreiros, H., Tonin, M., Vlassopoulos, M. and Schraefel, M.C. (2017). Now that you mention it: A survey experiment on information, inattention and online privacy, Journal of Economic Behavior \& Organization, Vol. 140, pp. 1-17.

Milne, G.R. and Culnan, M.J., (2004). Strategies for reducing online privacy risks: Why consumers read (or don't read) online privacy policies. Journal of Interactive Marketing, Vol. $18 \mathrm{~N}^{\circ}$ 3, pp. 15-29.

Miltgen, C. L., and Peyrat-Guillard, D. (2014). Cultural and generational influences on privacy concerns: A qualitative study in seven European countries. European Journal of Information Systems, Vol.23 N², pp. 103-125.

Mosteller, J. and Poddar, A. (2017). To share and protect: using regulatory focus theory to examine the privacy paradox of consumers' social media engagement and online privacy protection behaviors. Journal of Interactive Marketing, Vol. 39, pp. 27-38.

Mukherjee, S., Manjaly, J. and Nargundkar, M. (2013). Money makes you reveal more: consequences of monetary cues on preferential disclosure of personal information, Frontiers in Psychology, Vol. 4, 839, pp.1-5.

Novak, G. and Phelps, J. (1995). Understanding privacy concerns, Journal of Direct Marketing, Vol. $6 \mathrm{~N}^{\circ} 4$, pp.28-39. 
Olivero, N. and Lunt, P. (2004). Privacy versus willingness to disclose in e-commerce exchanges: The effect of risk awareness on the relative role of trust and control. Journal of Economic Psychology, Vol. $25 \mathrm{~N}^{\circ}$ 2, pp. 243-262.

Otto, P., Anton, A. and Baumer, D. (2006). The ChoicePoint dilemma: How data brokers should handle the privacy of personal information, North Carolina State University Technical Report TR-2006-18, pp. 1-12.

Phelps, J., Nowak, G. and Ferrell, E. (2000). Privacy concerns and consumer intention to provide personal information. Journal of Public Policy and Marketing, Vol. $19 \mathrm{~N}^{\circ} 1$, pp. $27-41$.

Poels, K. and Dewitte, S. (2008). Hope and self-regulatory goals applied to an advertising context: Promoting prevention stimulates goal-directed behaviour. Journal of Business Research, Vol. $61 \mathrm{~N}^{\circ}$ 10, pp. 1030-1040.

Premazzi, K., Castaldo, S., Grosso, M., Raman, P., Brudvig, S. and Hofacker, C. (2010). Customer information sharing with e-vendors: The roles of incentives and trust. International Journal of Electronic Commerce, Vol. $14 \mathrm{~N}^{\circ} 3$, pp. 63-91.

Prince, C. (2018). Do consumers want to control their personal data? Empirical evidence, International Journal of Human-Computer Studies, Vol. 110, pp. 21-32.

Taylor, D., Davis, D. and Jillapalli, R.(2009). Privacy concern and online personalization: the moderating effects of information control and compensation, Electronic Commerce Research, Vol. 9, pp.203-223.

Wang, J. and Lee, A Y. (2006). The role of regulatory focus in preference construction. Journal of Marketing Research, Vol. 43 N 1, pp. 28-38.

Ward, S., Bridges, K. and Chitty, B. (2005). Do incentives matter? An examination of online privacy concerns and willingness to provide personal and financial Information. Journal of Marketing Communications, Vol. $11 \mathrm{~N}^{\circ}$ 1, pp. 21-40.

Wirtz, J. and Lwin, M.O. (2009). Regulatory focus theory, trust and privacy concern. Journal of Service Research, Vol. $12 \mathrm{~N}^{\circ}$ 2, pp. 190-207.

Wu, K., Huang, S.Y., Yen, D.C. and Popova, I. (2012). The effect of online privacy policy on consumer privacy concern and trust. Computers in Human Behavior, Vol. $28 \mathrm{~N}^{\circ} 3$, pp. 889-897.

Xu, H., Teo, H.H., Tan, B.C. and Agarwal, R. (2009). The role of push-pull technology in privacy calculus: the case of location-based services. Journal of Management Information Systems, Vol. $26 \mathrm{~N}^{\circ} 3$, pp. 135-174.

ZDNet (2016) “Chiffres Clés: les navigateurs Internet”, ZDNet. Consulted in June 2016. http://www.zdnet.fr/actualites/chiffres-cles-les-navigateurs-internet-39381322.htm 